08

\title{
Структура, проводящие и отражающие свойства аморфных гранулированных композитных пленок $\left(\mathrm{Co}_{45} \mathrm{Fe}_{45} \mathrm{Zr}_{10}\right)_{x}(\mathrm{ZrO})_{1-x}$
}

\author{
(C) И.В. Антонец, ${ }^{1}$ Л.Н. Котов, ${ }^{1,}$ Е.А. Голубев, ${ }^{2}$ Ю.Е. Калинин, ${ }^{3}$ А.В. Ситников ${ }^{3}$ \\ ${ }^{1}$ Сыктывкарский государственный университет им. Питирима Сорокина, \\ 167001 Сыктывкар, Россия \\ ${ }^{2}$ Институт геологии Коми научного центра УрО РАН, \\ 167982 Сыктывкар, Россия \\ ${ }^{3}$ Воронежский государственный технический университет, \\ 394026 Воронеж, Россия \\ Ie-mail: kotovIn@mail.ru
}

(Поступило в Редакцию 11 мая 2016 г.)

\begin{abstract}
Приведены результаты исследования микро- и наноструктуры аморфных гранулированных композитных пленок состава $\left(\mathrm{Co}_{45} \mathrm{Fe}_{45} \mathrm{Zr}_{10}\right)_{x}(\mathrm{ZrO})_{1-x}, 0.27<x<0.61$, толщиной $328-772 \mathrm{~nm}$, нанесенных в атмосфере азота на лавсановую подложку. Результаты получены с использованием атомно-силовой, магнитно-силовой и сканирующей электронной микроскопии. Показано, что средние размеры зерен и содержание металлической фазы определяют их проводящие и отражающие свойства в диапазоне СВЧ.
\end{abstract}

DOI: 10.21883/JTF.2017.02.44131.1885

\section{Введение}

С развитием нанотехнологий исследованиям рельефа поверхности многослойных и композитных структур, тонких металлических пленок и сплавов, выращенных различными методами и нанесенных на подложки из различных материалов, выявлению новых особенностей структуры, а также их влиянию на различные свойства уделяется значительное внимание [1-15]. Особое место в этих исследованиях занимают аморфные пленки [16-20], отличающиеся уникальными свойствами по сравнению с их кристаллическими аналогами.

Как показано в работах [11-15,21-23] на примере тонких рентгеноаморфных металлических пленок, размеры зерен, кластеров и других поверхностных неоднородностей коррелируют с такими параметрами, как проводимость и коэффициент отражения СВЧ волн. Так, например, для пленок, имеющих кластерное строение, в работах $[12,21,23]$ выявлена зависимость удельной проводимости от толщины пленки и от размеров кластеров. В работах $[13,14,21-23]$ показано, что наноструктура металлических и металл-диэлектрических пленок определяет не только их проводящие, но и отражающие свойства.

Влияние микро- и наноструктур на проводящие и отражающие свойства активно исследуется и для аморфных гранулированных композитов [5,10,11,19,20,24-26].

Выбор объекта исследования обусловлен уникальной особенностью его проводящих свойств. В работах [24-26] выявлено, что динамическая проводимость в диапазоне СВЧ, определяемая по коэффициенту отражения электромагнитных волн, пленок состава
$\left(\mathrm{Co}_{45} \mathrm{Fe}_{45} \mathrm{Zr}_{10}\right)_{x}\left(\mathrm{Zr}_{2} \mathrm{O}_{3}\right)_{1-x}$ толщиной $70-550 \mathrm{~nm}$, нанесенных на лавсановую подложку, превышает статическую, измеренную на постоянном токе, на 2-4 порядка, еще до порога перколяции металлической фазы. А, например, для пленок $\left(\mathrm{Co}_{45} \mathrm{Fe}_{45} \mathrm{Zr}_{10}\right)_{x}\left(\mathrm{Al}_{2} \mathrm{O}_{3}\right)_{1-x}$ толщиной 2.2-5.8 $\mu \mathrm{m}$, нанесенных на подложку из ситалла, это превышение достигает всего нескольких раз [27].

В связи с этим особый интерес вызывает исследование рельефа поверхности аморфных гранулированных композитных пленок и выявление возможной взаимосвязи между микро- и наноструктурой, проводящими и отражающими свойствами. Исследована структура пленок $\left(\mathrm{Co}_{45} \mathrm{Fe}_{45} \mathrm{Zr}_{10}\right)_{x}\left(\mathrm{Al}_{2} \mathrm{O}_{3}\right)_{1-x}$ [10] и $\left(\mathrm{Co}_{45} \mathrm{Fe}_{45} \mathrm{Zr}_{10}\right)_{x}\left(\mathrm{Zr}_{2} \mathrm{O}_{3}\right)_{1-x} \quad[11] \quad$ с использованием атомно-силовой, магнитно-силовой и сканирующей электронной микроскопии. Результаты показывают, что такие параметры структуры, как средние размеры зерен и содержание металлической фазы, определяют их проводящие свойства, а зависимости проводимости и среднего размера зерен от содержания металлической фазы корреллируют между собой.

Настоящая работа является продолжением цикла работ по исследованиям аморфных наногранулированных композитных пленок. Цель ее заключается в исследованиях методами атомно-силовой, магнитно-силовой и сканирующей электронной микроскопии рельефа, микро- и наноструктуры, свойств поверхности серии композитных пленок состава $\left(\mathrm{Co}_{45} \mathrm{Fe}_{45} \mathrm{Zr}_{10}\right)_{x}(\mathrm{ZrO})_{1-x}$, нанесенных на подложку из лавсана, и в выявлении взаимосвязи структуры с проводящими и отражающими свойствами в области СВЧ. 
Толщина пленок, содержание элементов, средний размер зерен, проводимость и коэффициент отражения аморфных композитных пленок

\begin{tabular}{r|c|c|c|c|c}
\hline № & $\begin{array}{c}\text { Толщина } \\
d, \mathrm{~nm}\end{array}$ & $\begin{array}{c}\text { Содержание } \\
\text { Fe+Co+Zr, } \\
\text { Me, at.\% }\end{array}$ & $\begin{array}{c}\text { Средний раз- } \\
\text { мер зерен } \\
\Phi, \mathrm{nm}\end{array}$ & $\begin{array}{c}\text { Проводимость } \\
\sigma, \Omega^{-1} \mathrm{~m}^{-1}\end{array}$ & $\begin{array}{c}\text { Коэффициент } \\
\text { отражения } R \\
\text { на } f=8 \mathrm{GHz}\end{array}$ \\
\hline 1 & 336 & 26.84 & $-{ }^{*}$ & $2.68 \cdot 10^{-4}$ & - \\
2 & 410 & 31.68 & $1.28 \cdot 10^{-2}$ & $-1.49 \cdot 10^{-4}$ \\
3 & 328 & 34.00 & - & $2.67 \cdot 10^{-1}$ & $1.45 \cdot 10^{-4}$ \\
4 & 562 & 36.71 & - & $8.35 \cdot 10^{-1}$ & $3.51 \cdot 10^{-4}$ \\
5 & 665 & 40.50 & - & - & $1.80 \cdot 10^{-2}$ \\
6 & 451 & 40.59 & $16 \pm 3$ & $1.23 \cdot 10^{1}$ & $5.28 \cdot 10^{-2}$ \\
7 & 673 & 45.43 & $20 \pm 3$ & $2.29 \cdot 10^{3}$ & $2.33 \cdot 10^{-1}$ \\
8 & 545 & 48.36 & $11 \pm 1$ & $3.41 \cdot 10^{2}$ & $5.89 \cdot 10^{-1}$ \\
10 & 711 & 56.83 & $15 \pm 1$ & $3.09 \cdot 10^{3}$ & $5.66 \cdot 10^{-1}$ \\
11 & 510 & 56.98 & $23 \pm 3$ & $1.89 \cdot 10^{3}$ & $6.47 \cdot 10^{-1}$ \\
12 & 600 & 57.01 & $23 \pm 3$ & $6.80 \cdot 10^{3}$ & $6.76 \cdot 10^{-1}$ \\
14 & 772 & 58.08 & $20 \pm 3$ & $5.30 \cdot 10^{4}$ & $7.49 \cdot 10^{-1}$
\end{tabular}

* - Значение не определялось.

\section{1. Методика получения и характеристика исследуемых образцов}

Композитные гранулированные пленки состава $\left(\mathrm{Co}_{45} \mathrm{Fe}_{45} \mathrm{Zr}_{10}\right)_{x}(\mathrm{ZrO})_{1-x}$ (где $\left.x \sim 0.27-0.61\right)$ получены в атмосфере азота при давлении 0.024 Ра на лавсановой подложке толщиной $0.02 \mathrm{~mm}$ и размером $21 \times 28 \mathrm{~cm}^{2}$. Пленки изготовлены в Воронежском государственном техническом университете методом ионно-лучевого напыления. Методика получения пленок подробно описана в работах $[19,20]$. Для осаждения аморфной ферромагнитной металлической фазы композитов использовалась сплавная мишень состава $\mathrm{Co}_{45} \mathrm{Fe}_{45} \mathrm{Zr}_{10}$. На ее поверхности были закреплены навески ZrO. Изменение числа пластин диэлектрика и расстояния между ними позволяло изменять соотношение объемов напыляемых магнитного и диэлектрических слоев, управляя, таким образом, соотношением долей металл-диэлектрик. При этом неравномерное расположение пластин оксида циркония на поверхности мишени давало возможность получить непрерывный спектр составов компонент мишени вдоль ее длины в одном технологическом цикле нанесения. Толщина напыляемого слоя определялась временем напыления, которое составляло $120 \mathrm{~min}$. Время чистки поверхности лавсана ионным пучком $30 \mathrm{~min}$. Общее давление в камере до напыления и после очистки лавсана $-1.8 \cdot 10^{-2} \mathrm{~Pa}$. Давление азота $\mathrm{N}_{2}$ в камере $-2.4 \cdot 10^{-3} \mathrm{~Pa}$.

После формирования на подложке непрерывно меняющейся по толщине композитной пленки подложка разрезалась. Это позволило получить 14 образцов композитных пленок толщиной 328-772 nm, параметры которых приведены в таблице. Толщина оценивалась по изображениям энергий отраженных электронов от торца пленок с помощью сканирующего электронного микроскопа (СЭМ). Гранулированный (зернистый) характер металлических включений в композитных пленках определялся методом просвечивающей электронной микроскопии, аморфное строение - по высокой степени размытия кольцевых дифракционных гало на электронных микрофотографиях $[19,20]$.

\section{2. Техника и методика эксперимента}

\section{1. Определение толщины композитных пленок}

Толщины пленок определялись с помощью СЭМ TescanVega LMH (Чехия) с энергодисперсионным детектором X-MAX (Oxford Instruments). Измерения проводились на вырезанных фрагментах пленок с длиной стороны $1 \mathrm{~cm}$. Механизмы определения толщины по электронно-микроскопическим изображениям торца скола композитной пленки описаны в работах [10,11]. Участки выбирались равномерно по всей длине измеряемого фрагмента пленки, затем строилось размерное распределение толщин и рассчитывались модальная величина толщины пленки (соответствующая максимуму указанного распределения) и дисперсия.

\section{2. Элементный анализ композитных пленок}

Для количественного определения элементного состава поверхности пленок использовалась рентгеновская энергодисперсионная спектрометрия (система микроанализа AZTEC с детектором X-Max 50, кремнийдрейфовый детектор активной площадью $10 \mathrm{~mm}^{2}$, разрешение на линии $\left.\mathrm{Mn} K_{\alpha}-127 \mathrm{eV}\right)$, при которой образец 
бомбардируется высокоэнергетическими электронами, в результате чего с его поверхности происходит эмиссия рентгеновского излучения. Анализ характеристического рентгеновского излучения позволяет определить, какие элементы входят в состав образца и в каких количественных соотношениях они состоят путем сравнения интенсивности рентгеновских линий, генерируемых в образце, с интенсивностями соответствующих линий в стандартном образце (эталоне) при идентичных аналитических условиях. Энергодисперсионная спектрометрия проводилась при токе эмиссии $100 \mu \mathrm{A}$, токе образца $100 \mathrm{pA}$ и ускоряющем потенциале $20 \mathrm{kV}$. Диаметр пучка при элементном анализе составлял около $100 \mathrm{~nm}$. Время накопления сигнала $120 \mathrm{~s}$. Обработка данных рентгеноспектрального анализа осуществлялась с помощью программного приложения AZTEC (Oxford Instruments).

\section{3. Исследование топографии композитных пленок}

Исследование топографии поверхности образцов проводилось с помощью атомно-силового микроскопа (ACM) Интегра Prima (NT-MDT, Россия) в полуконтактном и контактном режимах. Для топографического сканирования применялись кантилеверы NC10 (NT-MDT) с радиусом закругления зонда около $10 \mathrm{~nm}$. Съемки проводились в комнатных условиях. Для исключения влияния электростатических эффектов на получаемые изображения пленки в процессе съемки были заземлены.

\section{4. Магнитно-силовая микроскопия композитных пленок}

Для определения магнитных областей на поверхности пленок использовались кантилеверы MFM10 (NT-MDT), силиконовый зонд, покрытый магнитным сплавом $\mathrm{CoCr}$, толщиной $40 \mathrm{~nm}$. Радиус закругления зонда - около $30 \mathrm{~nm}$. Принцип получения изображения структуры магнитных доменов пленок описан в [10]. Частота колебаний внешней силы, действующей на кантилевер и на зонд, составляла $47-90 \mathrm{kHz}$. Разность фаз между внешней силой и собственными колебаниями зонда изменялась в зависимости от силы магнитного взаимодействия зонда и области поверхности пленок. Зависимость разности фаз от координат поверхности преобразовывалась в изображение, называемое магнитным фазовым контрастом, отображающее размеры и форму магнитных металлических областей пленки. Радиус закругления кончика зонда определял разрешение, которое позволяло на магнитном фазовом контрасте отдельно видеть магнитные (металлические) области с размерами в $10-15 \mathrm{~nm}$.

\section{5. Исследование проводимости композитных пленок}

Удельная проводимость определялась по обратной величине удельного электрического сопротивления, измеряемого на постоянном токе двузондовым методом с использованием потенциометрической методики замещения $[12,13,22,24-26]$.

По известной толщине пленок с учетом геометрического фактора производился пересчет измеряемого сопротивления образца в удельную проводимость.

\section{6. Исследование коэффициента отражения композитных пленок}

Коэффициент отражения СВЧ сигнала от тонких пленок при нормальном падении волны измерялся в диапазоне частот 8-12 GHz. Исследуемая пленка помещалась в прямоугольный волновод сечением $10 \times 24 \mathrm{~mm}$ перпендикулярно его продольной оси. Пленка перекрывала все сечение волновода. На другом конце волновода позади пленки находилась согласованная нагрузка. В качестве генератора качающей частоты использовался ГКЧ Р2-65, входящий в состав комплекса панорамного измерителя коэффициента стоячих волн (КСВН). Зависимость КСВН от частоты для данного образца отображалась на индикаторе КСВН и ослабления Я2Р-67. Методика измерения коэффициента отражения описана в [13].

\section{3. Основные результаты экспериментов и их обсуждение}

\section{1. Топография аморфных композитных пленок $\left(\mathrm{Co}_{45} \mathrm{Fe}_{45} \mathrm{Zr}_{10}\right)_{x}(\mathrm{ZrO})_{1-x}$}

Общей характеристикой всех пленок являлась их неоднородность, проявляющаяся в присутствии на поверхности многочисленных уплощенных островков (капель) разнообразных форм с размерами от десятка до нескольких сотен нанометров (рис. 1). Капли располагались с высокой плотностью, средние расстояния между ними составляли 50-100 nm, на участке $1 \times 1 \mu \mathrm{m}$ находилось два-три десятка капель. На поверхности пленок зачастую отчетливо проступал волокнистый рельеф лавсановой подложки с диаметром волокон около $80-100 \mathrm{~nm}$ (рис. 2). Кроме того, наблюдались наследуемые от подложки пересекающиеся борозды протяженностью от единиц до десятков микромеров. Вплоть до пленки № 4 на поверхности встречались разрывы сплошности пленочного покрытия, как правило, в виде округлых пор. Начиная с пленки № 5, наблюдалось уже сплошное покрытие поверхности подложки напыленным материалом. Пленка по структуре представляет собой плотно упакованные, практически сливающиеся гранулы (рис. 3), размеры которых незначительно варьируют с толщиной пленок. Обособленные гранулы отчетливо 


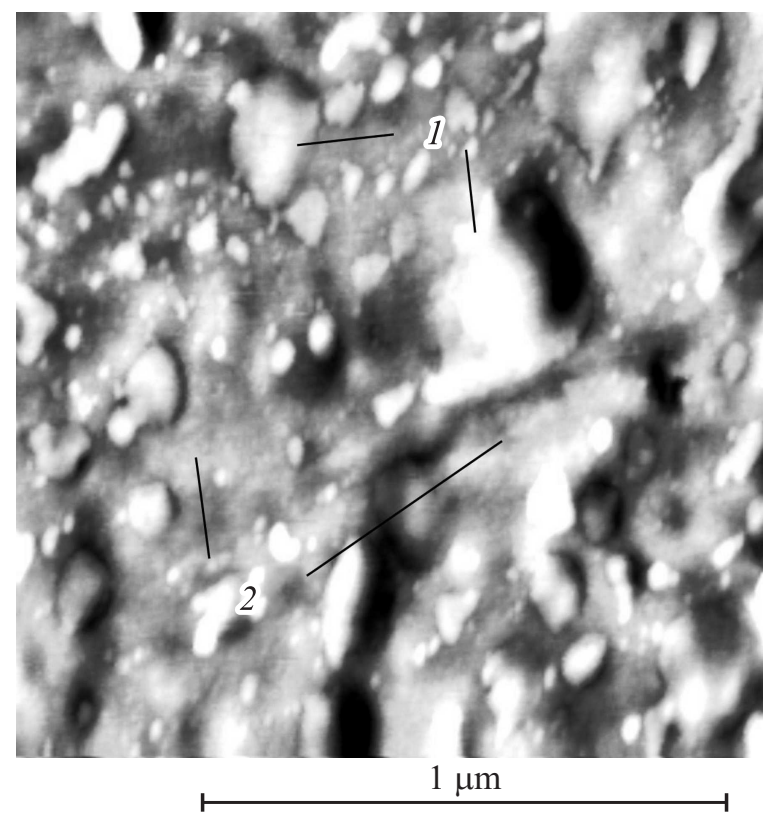

Рис. 1. Типичное АCM изображение поверхности пленок (пленка № 7): 1 - капли на поверхности пленки, 2 гранулированная пленка.

просматривались на изображениях только начиная с пленки № 7, до этого гранулярное строение проявлялось лишь как наноразмерная шероховатость поверхности на участках сплошного покрытия пленкой поверхности подложки (рис. 3,a). На АСМ-изображениях гранулы наиболее четко проявляются в углублениях, которые, вероятно, связаны с межволоконной пористостью лавсановой подложки.

В пленках № 10, 11, 13, 14 методом магнитно-силовой микроскопии была выявлена магнитная доменная структура. Типичные структуры магнитных доменов в этих пленках показаны на рис. 4. Пленки № 11,13,14 имеют однородно упорядоченную, протяженную полосовую доменную структуру (рис. $4, a-c$ ). Известно, что присутствие такой доменной структуры является показателем наличия в пленке перпендикулярной магнитной анизотропии [28,29]. В пленках с наивысшим содержанием металлов № 13 и 14 (рис. 4, $a, b$ ) период доменной структуры составлял около $150 \mathrm{~nm}$. В пленке, с чуть меньшим содержанием металлов, № 11 (рис. 4, с) этот период увеличивался в среднем до $200 \mathrm{~nm}$. При этом доменная структура сильно зависит от структуры самой пленки, что наглядно проявляется на МСМ изображении пленки № 11. На тех участках, где наблюдается существенное влияние на гранулярную структуру пленки элементов рельефа подложки, прежде всего в виде борозд и валов, полосовая доменная структура переходит в слабоупорядоченную (упорядоченность здесь связана со статистической ориентированностью доменов в одном направлении) лабиринтную структуру с увеличенным расстоянием между доменами. На участках

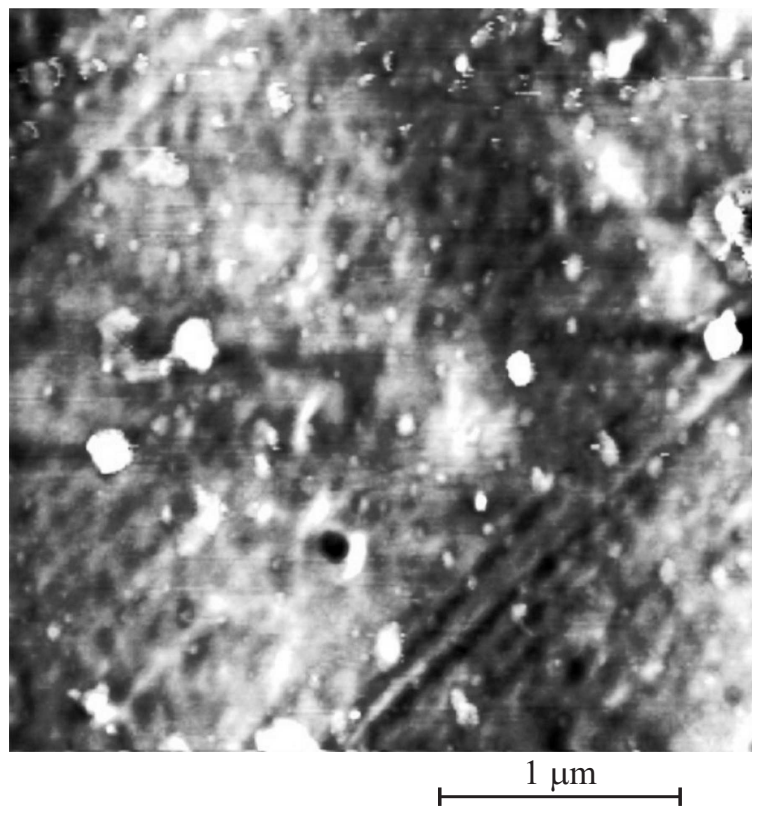

Рис. 2. Отпечатки волокнистых форм строения лавсановой подложки на поверхности пленки № 4.

упорядоченного строения наблюдались разрывы полос, топографически связанные с крупными каплями-бугорками на поверхности пленок. Вероятно, концентрации металла в этих бугорках существенно меньше, чем в остальном объеме пленки. Также нарушения полосовой доменной структуры проявлялись в виде раздвоения полос. Пленка № 10 (рис. 4,d) имеет неупорядоченную доменную структуру, характерную для пленок, намагниченность которых лежит в плоскости пленки - в виде разноразмерной сетки с широким разбросом расстояний между доменами (от 200 до $500 \mathrm{~nm}$ ). Как и в пленках с полосовой доменной структурой, увеличенные расстояния между доменами связаны в основном с элементами рельефа пленки в виде капель-бугорков.

\section{2. Толщина, содержание металлической фазы и средний размер зерен аморфных композитных пленок}

Результаты определения толщин, содержания металлической фазы и среднего размера зерен для аморфных композитных пленок приведены в таблице. На рис. 5, 6 показаны зависимости среднего размера зерен $\Phi$ от толщины $d$ (рис. 5) и от содержания металлической фазы Ме (рис. 6).

Как было показано выше, до пленки № 7 отчетливого гранулярного строения не просматривалось, зерна проявлялись лишь на уровне шероховатости, и измерить среднестатистические размеры не удалось. Поэтому на рис. 5,6 представлены экспериментальные точки лишь 9 пленок (с № 7 по № 14 и пленки № 3). 

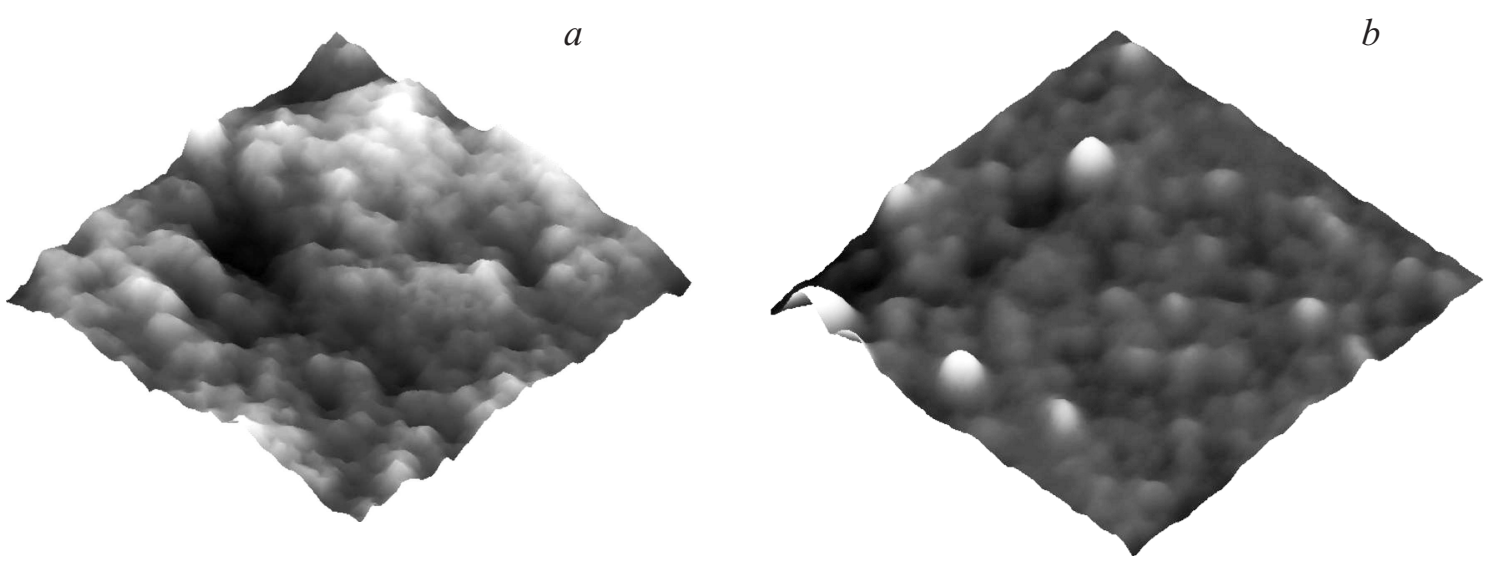

Рис. 3. Гранулированное строение пленок: $a-$ пленка № 3, $b-$ пленка № 8 . Размер скана $-450 \times 450 \mathrm{~nm}$.

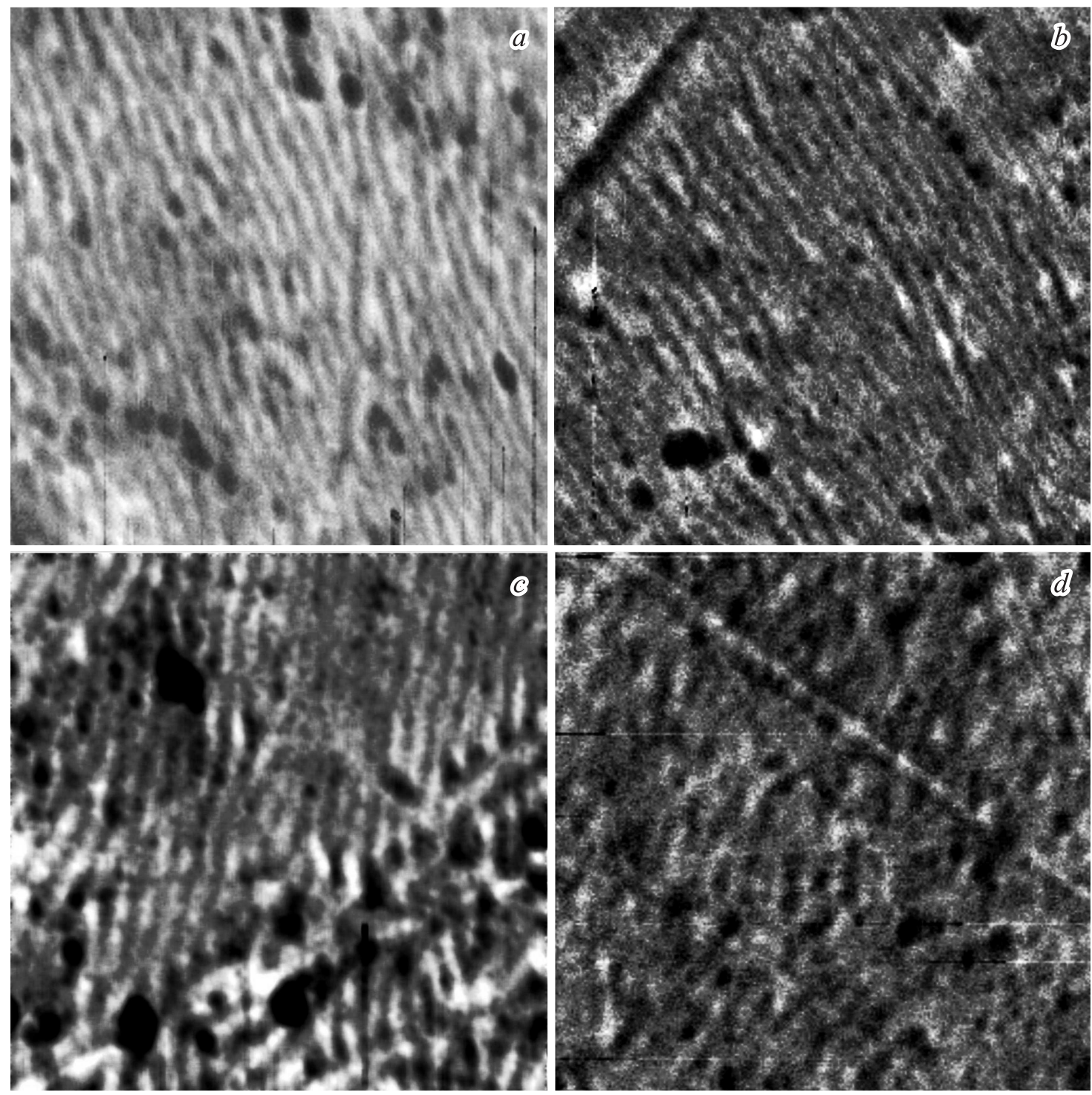

Рис. 4. МСМ изображения структуры магнитных доменов в пленках: $a$ - пленка № 13, $b$ - пленка № 14 , $c$ - пленка № 11 , $d-$ пленка № 10. Размер скана $-3 \times 3 \mu \mathrm{m}$. 


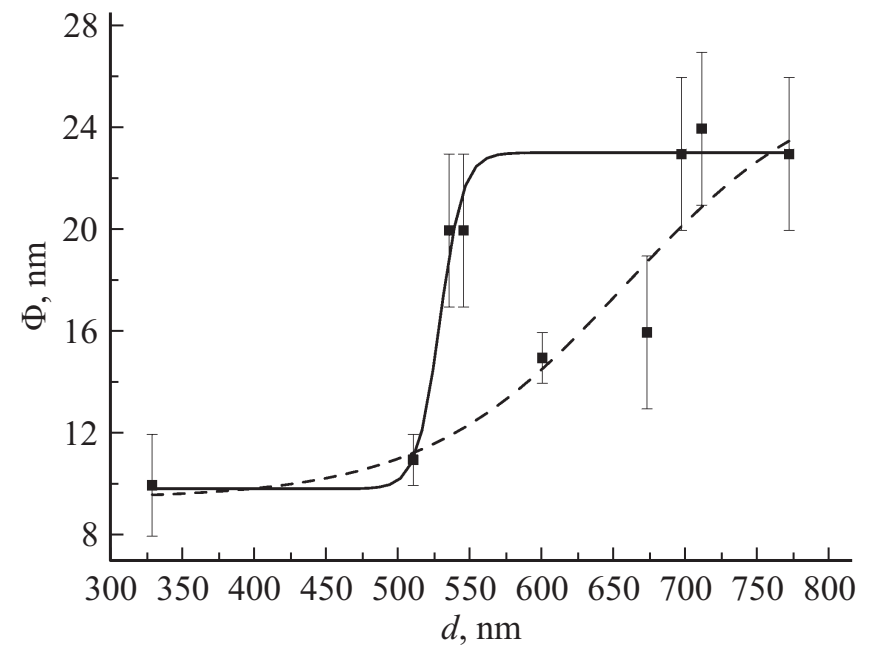

Рис. 5. Зависимость средних размеров зерен $\Phi$ от толщины $d$ в аморфных композитных пленках. Экспериментальные точки аппроксимированы функцией (1) с параметрами: сплошная кривая $-A_{1}=9.78 \mathrm{~nm}, A_{2}=23.11 \mathrm{~nm}, x_{0}=528.43 \mathrm{~nm}$, $d x=8.29 \mathrm{~nm}$, штриховая - $A_{1}=9.82 \mathrm{~nm}, A_{2}=24.08 \mathrm{~nm}$, $x_{0}=638.29 \mathrm{~nm}, d x=53.57 \mathrm{~nm}$.

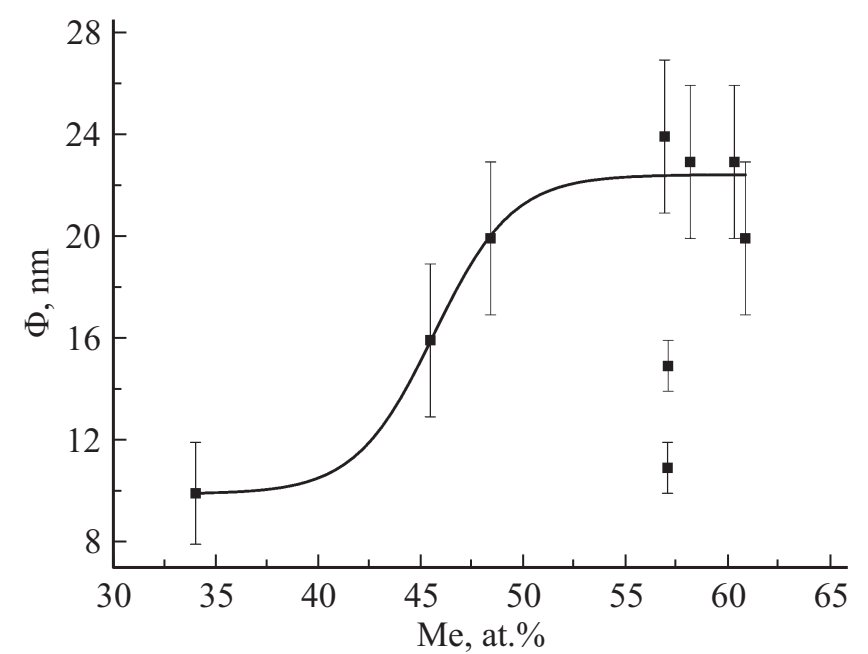

Рис. 6. Зависимость средних размеров зерен $\Phi$ от содержания металлической фазы Ме в аморфных композитных пленках. Экспериментальные точки аппроксимированы функцией (1) с параметрами $A_{1}=9.97 \mathrm{~nm}, A_{2}=22.50 \mathrm{~nm}, x_{0}=45.60$ at.\%, $d x=1.91$ at. $\%$.

Как видно из рис. 5, определить однозначную зависимость $\Phi(d)$ весьма затруднительно. Наиболее вероятное поведение среднестатистического размера зерен с толщиной (сплошная кривая на рис. 5) описывается функцией $[10,11]$

$$
y(x)=\frac{A_{1}-A_{2}}{1-\exp \left(\frac{x-x_{0}}{d x}\right)}+A_{2},
$$

где $y(x)=\Phi(d), \quad A_{1}=9.78 \mathrm{~nm}, \quad A_{2}=23.11 \mathrm{~nm}, \quad x_{0}=$ $=528.43 \mathrm{~nm}, d x=8.29 \mathrm{~nm}$.
В пользу данного предположения говорит тот факт, что именно этой функцией для аморфных наногранулированных композитов $\left(\mathrm{Co}_{45} \mathrm{Fe}_{45} \mathrm{Zr}_{10}\right)_{x}\left(\mathrm{Zr}_{2} \mathrm{O}_{3}\right)_{1-x}$ описывалось поведение среднего размера зерен с толщиной $\Phi(d)$ и содержанием металлической фазы $\Phi(\mathrm{Me})$ для $\left(\mathrm{Co}_{45} \mathrm{Fe}_{45} \mathrm{Zr}_{10}\right)_{x}\left(\mathrm{Al}_{2} \mathrm{O}_{3}\right)_{1-x}[10,11]$, а также для тонких пленок различных металлов и металл-диэлектрических пленок изменение проводимости с толщиной $\sigma(d)[13,21,23]$.

Из заданной кривой аппроксимации выпадают две экспериментальные точки для пленок № $11(d=600 \mathrm{~nm})$ и № $7(d=673 \mathrm{~nm})$. Используя эти точки, можно построить другую вероятную кривую по формуле (1), описывающую поведение $\Phi(d)$ (штрих на рис. 5). Параметры кривой: $y(x)=\Phi(d), A_{1}=9.82 \mathrm{~nm}, A_{2}=24.08 \mathrm{~nm}$, $x_{0}=638.29 \mathrm{~nm}, d x=53.57 \mathrm{~nm}$. В этом случае также имеются две точки выброса: для пленки № 14 $(d=545 \mathrm{~nm})$ и № $8(d=535 \mathrm{~nm})$. При этом отклонение точек от аппроксимационной кривой значительно возрастает.

В работе [10] высказано предположение, что основным параметром, в зависимости от которого следует исследовать проводящие, отражающие и другие свойства аморфных композитных пленок, является не толщина, а содержание металлической фазы в случае, если Ме отличается до 2.5 раза. В нашем случае толщина пленок и содержание металлической фазы изменяются практически одинаково (в 2.35 и 2.26 раза соответственно), поэтому исследование свойств пленок от Ме весьма оправдано.

На рис. 6 представлена зависимость размеров зерен $\Phi$ от содержания металлической фазы для аморфных композитных пленок. Экспериментальные точки аппроксимированы функцией (1) с параметрами $y(x)=\Phi(\mathrm{Me}), A_{1}=9.97 \mathrm{~nm}, A_{2}=22.50 \mathrm{~nm}, x_{0}=$ $=45.60$ at. $\%, d x=1.91$ at.\%. На рис. 6 также заметны две экспериментальные точки, не укладывающиеся в общий вид зависимости: для пленок № 10 (Ме = $=56.98$ at.\%) и № 11 (Me = 57.01 at.\%), причем одна из этих точек (пленка № 11) совпадает с точкой выброса на рис. 5 (сплошная кривая). Это подтверждает предположение о том, что наиболее вероятная зависимость $\Phi(d)$ описывается сплошной кривой на рис. 5.

Из рис. 5,6 следует, что средние размеры зерен имеют ярко выраженную зависимость как от толщины, так и от содержания металлической фазы, начиная с $d=510 \mathrm{~nm}$ и Ме $\sim 42 \pm 2$ at.\%, и увеличиваются с ростом $d$ и Ме. При этом размер зерен изменяется в 2.1 раза с 11 до $23 \mathrm{~nm}$. В работе [10] зависимость $\Phi$ от содержания металлической фазы была обнаружена при аналогичных $\mathrm{Me} \sim 44$ at.\% для пленок $\left(\mathrm{Co}_{45} \mathrm{Fe}_{45} \mathrm{Zr}_{10}\right)_{x}\left(\mathrm{Al}_{2} \mathrm{O}_{3}\right)_{1-x}$, толщина которых в 6-8 раз превосходила исследуемые. Таким образом, как для тонких, так и для более толстых пленок существенный рост среднего размера зерен наблюдается при содержании металлической фазы около 44 at.\%. 


\section{3. Проводимость и коэффициент отражения аморфных композитных пленок $\left(\mathrm{Co}_{45} \mathrm{Fe}_{45} \mathrm{Zr}_{10}\right)_{x}(\mathrm{ZrO})_{1-x}$}

Результаты определения удельной проводимости и коэффициента отражения на частоте $8 \mathrm{GHz}$ для композитных пленок представлены в таблице. Выявлено, что удельная проводимость исследуемых пленок изменялась на восемь порядков от $10^{-4}$ до $10^{4} \Omega^{-1} \mathrm{~m}^{-1}$, причем ее увеличение сопровождалось в основном как увеличением содержания металлической фазы от 30 до 60\%, так и коэффициента отражения от $4.5 \cdot 10^{-4}$ до $7.4 \cdot 10^{-1}$.

На рис. 7,8 показаны зависимости проводимости $\sigma$ (рис. 7) и коэффициента отражения на частоте $8 \mathrm{GHz}$ (рис. 8) от содержания металлической фазы Ме для аморфных композитных пленок.

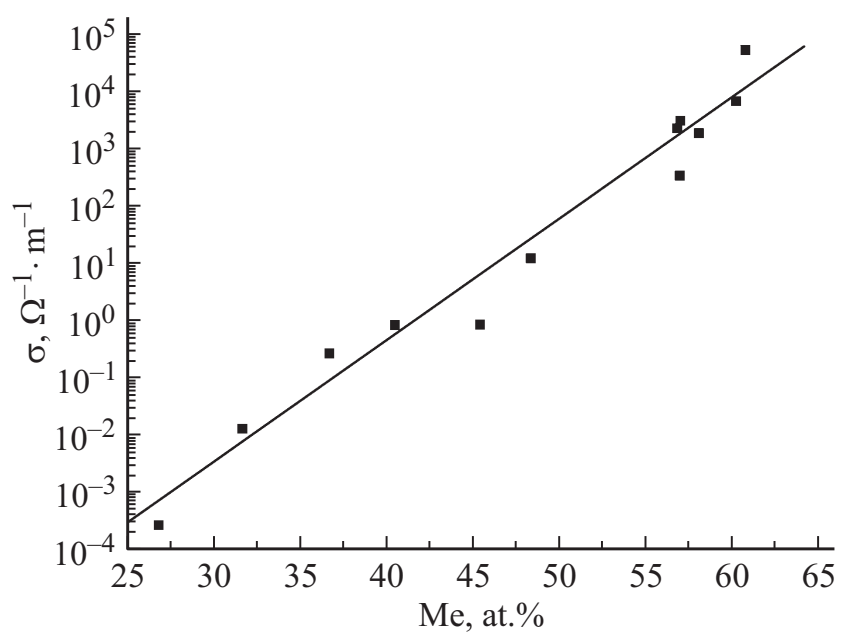

Рис. 7. Зависимость проводимости $\sigma$ от содержания металлической фазы Ме. Экспериментальные точки аппроксимированы функцией (2) с параметрами $A=-9.00, B=0.21$.

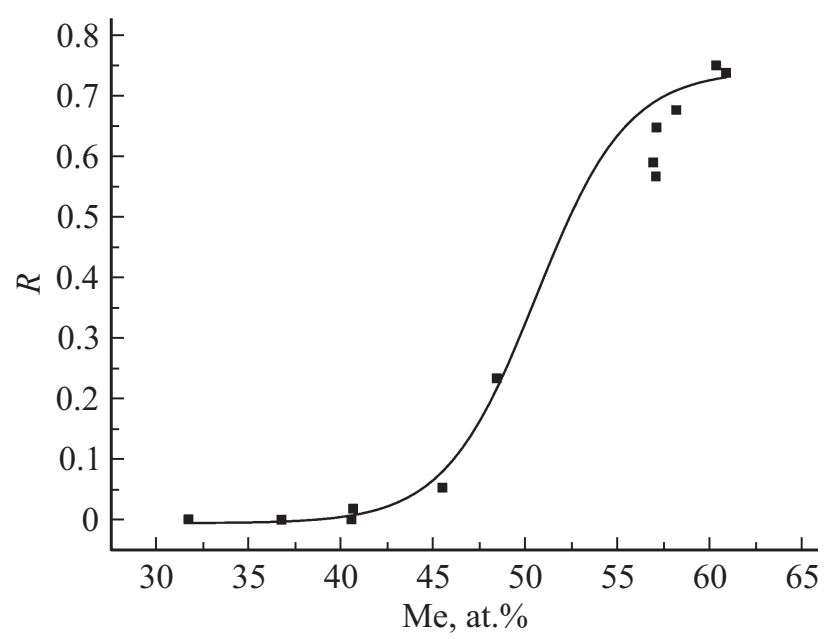

Pис. 8. Зависимость коэффициента отражения $R$ на частоте $8 \mathrm{GHz}$ от содержания металлической фазы Ме. Экспериментальные точки аппроксимированы функцией (1) с параметрами $A_{1}=0, A_{2}=0.74, x_{0}=50.49$ at. $\%, d x=2.47$ at. $\%$.
Как видно из рис. 7, экспериментальные точки проводимости с ростом Ме в логарифмическом масштабе распределяются вдоль прямой

$$
\sigma(\mathrm{Me})=A+B \cdot \mathrm{Me}
$$

где $A=-9.00, B=0.21$. Экспериментальная зависимость $R(\mathrm{Me})$ (рис. 8) хорошо аппроксимируется функцией (1), которой ранее описывалось изменение размеров зерен с толщиной и содержанием металлической фазы. Здесь $y(x)=R(\mathrm{Me}), A_{1}=0, A_{2}=0.74, x_{0}=50.49$ at.\%, $d x=2.47$ at. $\%$.

При Ме $<46$ at.\% разброс экспериментальных точек проводимости и, следовательно, отклонение от прямой (2) весьма заметны (рис. 7). При дальнейшем увеличении содержания металлической фазы точки упорядочиваются, несмотря на значительные отличия по толщине пленок, и распределение становится более линейным. Причем именно при $\mathrm{Me}>46$ at.\% (металл начинает занимать практически половину объема) проводимость становится металлической, а коэффициент отражения при увеличении проводимости растет, что и показывает рис. 8. Следует отметить, что в том же самом интервале при Ме $\sim(42-55) \pm 2$ at.\% значительно увеличился и размер зерен (в 2.1 раза) (рис. 6). Некоторое замедление роста $R(\mathrm{Me})$ наблюдается при $\mathrm{Me}>56$ at.\%. Однако в насыщение коэффициент отражения не выходит, так как проводимость во всем рассматриваемом диапазоне Ме продолжает увеличиваться (рис. 7, 8).

В работе [10] показано, что для аморфных композитных пленок $\left(\mathrm{Co}_{45} \mathrm{Fe}_{45} \mathrm{Zr}_{10}\right)_{x}\left(\mathrm{Al}_{2} \mathrm{O}_{3}\right)_{1-x}$ при содержании металлической фазы до формирования металлической проводимости (Ме $<44$ at.\%) с уменьшением среднего размера зерен наблюдается некоторый спад проводимости, несмотря на увеличение Ме. То есть именно одновременный рост содержания металлической фазы и размеров зерен определяет поведение как проводимости, так и коэффициента отражения.

При Мe $\geq 56$ at.\% наблюдается значительный разброс точек и отклонение от аппроксимирующих кривых как проводимости, так и коэффициента отражения (рис. 7, 8). По-видимому, это вызвано существенным отличием параметров пленок для этих содержаний металлической фазы. Так, практически при одних и тех же Ме (пленки № 9-11) толщины пленок могут отличаться на $200 \mathrm{~nm}$, размеры зерен более чем в 2 раза, а проводимость на порядок (см. таблицу).

Таким образом, для аморфных композитных пленок $\left(\mathrm{Co}_{45} \mathrm{Fe}_{45} \mathrm{Zr}_{10}\right)_{x}(\mathrm{ZrO})_{1-x}$ зависимости проводимости, коэффициента отражения и среднего размера зерен от содержания металлической фазы коррелируют между собой. Поведение коэффициента отражения описывается изменением проводимости аморфных композитных пленок, которая в свою очередь определяется одновременно особенностями их структуры и состава (параметрами $\Phi$ и Ме). 


\section{4. Основные результаты работы}

Исследована структура аморфных гранулированных композитных пленок $\left(\mathrm{Co}_{45} \mathrm{Fe}_{45} \mathrm{Zr}_{10}\right)_{x}(\mathrm{ZrO})_{1-x}$ на лавсановой подложке.

По данным атомно-силовой микроскопии структура всех пленок являлась неоднородной, на поверхности присутствовали многочисленные капли, отчетливо просматривался волокнистый рельеф лавсановой подложки. Вплоть до пленки № 4 на поверхности встречались разрывы, для более толстых пленок наблюдалось уже сплошное покрытие. Разрешение АСМ как с обычным зондом, так и с магнитным не позволяло зафиксировать гранулированную структуру, вплоть до пленки № 7. Это свидетельствует о хорошем перемешивании металлической и диэлектрической фаз для пленок с небольшой концентрацией металла.

Методом магнитно-силовой микроскопии визуализирована магнитная доменная структура пленок. Для ряда исследуемых пленок выявлена однородно упорядоченная полосовая доменная структура, которая сильно зависит от рельефа самой пленки. В пленках, в которых существенное влияние на гранулярную структуру оказывают элементы рельефа подложки, полосовая доменная структура переходит в слабоупорядоченную лабиринтную структуру. Для формирования полосовой доменной структуры на поверхности критическим является содержание металлической фазы, в частности кобальта. Изначально разупорядоченная, она проявляется только при Ме не менее 56 at.\%. С увеличением толщины пленки и содержания кобальта полосовая доменная структура пленок упорядочивается до субпараллельной с уменьшением периода от 200 до $150 \mathrm{~nm}$. Тем не менее структура поверхности пленки оказывает прямое воздействие на доменную структуру, что проявляется в нарушениях периодичности и разрывах полос, топографически связанных с нарушениями гранулярной структуры пленки.

Определена зависимость среднестатистических размеров зерен от толщины и содержания металлической фазы. Наиболее выраженные зависимости средние размеры зерен от толщины и от содержания металлической фазы имеют при $d>510 \mathrm{~nm}$ и $\mathrm{Me}>42 \pm 2$ at.\%. В соответствии с результатами предыдущих работ показано, что для тонких аморфных композитных пленок, как в настоящей работе, и для более толстых пленок, толщиной в 6-8 раз превосходящих рассматриваемые, значительный рост среднего размера зерен проявляется при содержании металлической фазы > 44 at.\%.

Выявлено, что от содержания металлической фазы Ме существенно изменяются проводимость $\sigma$ и коэффициент отражения $R$. В рассматриваемом интервале Ме от 26 до 61 at.\% удельная проводимость исследуемых пленок увеличилась на восемь порядков от $10^{-4}$ до $10^{4} \Omega^{-1} \mathrm{~m}^{-1}$, а коэффициент отражения более чем на три порядка от $4.5 \cdot 10^{-4}$ до $7.4 \cdot 10^{-1}$. В указанном интервале проводимость с ростом Ме в основном растет. При Ме $<46$ at.\% разброс экспериментальных точек проводимости весьма заметен, а при дальнейшем увеличении Ме распределение (в логарифмическом масштабе) становится более линейным.

Выявлен интервал содержаний металлической фазы $\mathrm{Me} \sim(42-55) \pm 2$ at.\%, при котором наблюдалась резкая зависимость размеров зерен $\Phi(\mathrm{Me})$ и коэффициента отражения $R(\mathrm{Me})$. Экспериментальные точки хорошо аппроксимируются функцией (1), которой для ряда других аморфных пленок описывались зависимости $\Phi(\mathrm{Me})$ и $\sigma(\mathrm{Me})$, а для тонких металлических, металл-диэлектрических пленок $-\Phi(d)$ и $\sigma(d)$.

Показано, что структура аморфных гранулированных композитных пленок определяет как их проводящие, так и отражающие свойства, а зависимости среднего размера зерен, проводимости и коэффициента отражения от содержания металлической фазы коррелируют между собой. Поведение коэффициента отражения описывается изменением проводимости аморфных композитных пленок, которая, в свою очередь, определяется одновременно особенностями их структуры и состава (параметрами Ф и Ме).

Авторы выражают глубокую признательность С.С. Шевчуку и В.А. Радаеву (Институт геологии Коми НЦ УрО РАН) за электронно- и зондовомикроскопические исследования композитных пленок.

\section{Список литературы}

[1] Бажин И.В., Лещева О.А., Никифоров И.Я. // ФТТ. 2006. T. 48. № 4. C. $726-731$.

[2] Грабов В.М., Демидов Е.В., Комаров В.А. // ФТТ. 2008. T. 50. № 7. C. $1312-1316$.

[3] Кукушкин C.A., Осипов А.В. // УФН. 1998. Т. 168. № 10. C. $1083-1116$.

[4] Муслимов А.Э., Буташин А.В., Коновко А.А., Смирнов И.С., Рощин Б.С., Волков Ю.О., Ангелуи А.А., Андреев А.В., Шкуринов А.П., Каневский В.М., Асадчиков В.Е. // Кристаллография. 2012. Т. 57. № 3. С. 471-476.

[5] Ганьшина Е.А., Кочнева М.Ю., Подгорный Д.А., Щербак П.Н., Демидович Г.Б., Козлов С.Н. // ФТТ. 2005. Т. 47. № 7. C. $1333-1337$.

[6] Серов И.Н., Марголин В.И., Потсар Н.А., Солтовская И.А., Фантиков В.С., Тупик В.А. // Поверхность. 2004. № 7. C. $31-35$.

[7] Житейщев Е.Р., Уланов В.А., Зарипов М.М., Жеглов Е.П. // ФТТ. 2005. Т. 47. № 7. С. 1212-1216.

[8] Du J.H., Le Q., Wang L.C. // J. Phys.: Condensed Matter. 1995. Vol. 7. P. $9425-9432$.

[9] Yates H.M., Brook L.A., Sheel D.W., Ditta I.B., Steele A., Foster H.A. // Thin Solid Films. 2008. Vol. 517. № 2. P. 517-521.

[10] Антонеи, И.В., Голубев Е.А., Котов Л.Н., Калинин Ю.Е., Ситников А.В. // ЖТФ. 2016. Т. 86. № 3. С. 98-105.

[11] Антонеи, И.В., Голубев Е.А., Котов Л.Н. // Известия Коми научного центра УрО РАН. 2015. № 1 (21). С. 13-21.

[12] Антонеи И.В., Котов Л.Н., Некипелов С.В., Голубев Е.А. // ЖТФ. 2004. Т. 74. № 3. С. 24-27. 
[13] Антонеи, И.В., Котов Л.Н., Некипелов С.В., Карпушов Е.Н. // ЖТФ. 2004. Т. 74. № 11. С. 102-106.

[14] Антонеи, И.В., Котов Л.Н., Макаров П.А., Голубев Е.А. // ЖТФ. 2010. Т. 80. № 9. С. 134-140.

[15] Антонеи, И.В., Котов Л.Н., Голубев Е.А. // Поверхность. Рентгеновские, синхротронные и нейтронные исследования. 2007. № 8. С. 65-71.

[16] Бек Г., Гюнтеродт Г.Й. Металлические стекла. М.: Наука, 1983. $454 \mathrm{c}$.

[17] Полухин В.А., Ватолин Н.А. Моделирование аморфных металлов. М.: Наука, 1985. 288 с.

[18] Луцев Л.В., Звонарева Т.К., Лебедев В.М. // Письма в ЖТФ. 2001. Т. 27. № 15. С. 84-89.

[19] Калинин Ю.Е., Пономаренко А.Т., Ситников А.В., Стогней O.B. // Физика и химия обработки материалов. 2001. № 5. C. 14-20.

[20] Золотухин И.В., Калинин Ю.Е., Неретин П.В., Ситников А.В., Стогней O.B. // Альтернативная энергетика и экология. 2002. № 2. С. 7-14.

[21] Антонеи, И.В. Отражающие и проводящие свойства тонких металлических пленок и их наноструктура. Сыктывкар: Изд-во Сыктывкарского гос. ун-та, 2007. 124 с.

[22] Антонеи, И.В., Котов Л.Н., Шавров В.Г., Щеглов В.И. // Радиотехн. и электрон. 2004. Т. 49. № 10. С. 1243-1250.

[23] Котов Л.Н., Антонеи И.В., Голубев Е.А., Петрунев С.Н. // Вестник Поморского гос. ун-та. Сер. „Естественные науки“. 2008. Т. 3. С. 50-57.

[24] Антонеи И.В., Котов Л.Н., Калинин Ю.Е., Ситников А.В., Шавров В.Г., Щеглов В.И. // Письма в ЖТФ. 2014. Т. 40. № 14. C. 1-6.

[25] Антонеи И.В., Котов Л.Н., Кирпичева О.А., Голубев Е.А., Калинин Ю.Е., Ситников А.В., Шавров В.Г., Щеглов В.И. // Радиотехн. и электрон. 2015. Т. 60. № 8. C. $839-850$.

[26] Антонеи, И.В., Котов Л.Н., Кирпичева О.А., Голубев Е.А., Калинин Ю.Е., Ситников А.В., Шавров В.Г., Щеглов В.И. // Журнал радиоэлектроники. Электронный журнал. 2014. № 4. Режим доступа: http://jre.cplire.ru/koi/apr14/12/

[27] Власов В.С., Котов Л.Н., Шавров В.Г., Щеглов В.И. // Радиотехн. и электрон. 2014. Т. 59. № 9. С. 882.

[28] Sulitanu N. // J. Magnetism and Magnetic Materials. 2001. Vol. 231. P. 85-93.

[29] Kohmoto O., Mineji N., Isagawa Y. // J. Magnetism and Magnetic Materials. 2002. Vol. 239. P. 36-38. 